\title{
A Review for Software Supportability Assessment of Military Equipment
}

\author{
Lv Huiwen ${ }^{1}$, Zhang Wei ${ }^{1}$, Ma Sasa ${ }^{2}$, Han Ning ${ }^{2}$, Chen Weiguo ${ }^{2}$ \\ ${ }^{1}$ Equipment Command Department of Equipment College, Beijing, China \\ ${ }^{2}$ Radar System Research Laboratory, PLA 63908, Shijiazhuang, China
}

Email address:

oec1jw2009@163.com (Lv Huiwen)

\section{To cite this article:}

Lv Huiwen, Zhang Wei, Ma Sasa, Han Ning, Chen Weiguo. A Review for Software Supportability Assessment of Military Equipment. Advances in Applied Sciences. Vol. 2, No. 1, 2017, pp. 7-10. doi: 10.11648/j.aas.20170201.12

Received: October 7, 2016; Accepted: October 29, 2016; Published: December 2, 2016

\begin{abstract}
Foreign and domestic research status of military equipment software supportability is analyzed. Quantitative research and qualitative research is adopted as the measurement principle to depart the research into two parts. The research status is studied from supportability process modelling, model analysis, qualitative comparison and parameters quantitative methods. The comprehensive analysis process of software supportability assessment is researched. The existing problems of current research status are analyzed and the upcoming research direction is put forward.
\end{abstract}

Keywords: Military Equipment, Software Supportability, Supportability Assessment

\section{Introduction}

With the development of science and technology, the high technology group centered about information technology gets rapid development. High and new technology finds wider and wider application in the field of military. Military theory, war forms and battle patterns have changed dramatically. To meet the demand of air-space integrative battle and combined war of various military categories, high performance, versatility and flexible tactical performance of weapon equipment is needed. In order to meet the diverse needs of future battlefield, software takes higher and higher application proportion in military equipment. Research data shows that software application proportion in equipment has been advanced from $10 \%$ to $40 \% \sim 50 \%$ since World War II. As for the command, control, and communication equipment, in which software takes up dominant status, the software proportion holds up to $80 \%$ indeed. In accordance with the development of weapon equipment, software maintenance has become a severe and difficult problem during the development process of equipment maintenance. How to improve software supportability, how to assess software supportability, how to realize the convenient maintenance of software, have all become the research hotspots. In this paper, the research status of software supportability for military equipment is analyzed. The domestic and foreign research progress is summarized and the existing problems are researched. Based on the above research, the upcoming research direction of software supportability is put forward.

\section{The Basic Concept of Software Support}

\subsection{Software Support}

Software support is all the activity which is used to make sure that the software could continually and fully guarantee the equipment could complete its task. All the activity runs through the whole life cycle of software, which could be divided into before-deployment support and afterdeployment support. Before-deployment support is mainly responsible for developing software with software developers cooperatively. And the function, maneuverability, reliability, maintainability, supportability and security are clarified. The demand check, software assessment, test and check are also discussed during before-deployment. After-deployment support is also called software maintenance, which is responsible for correction maintenance, perfection maintenance, precaution maintenance and so on [1].

\subsection{Software Supportability}

Software supportability is a kind of measurement, which is 
used to measure software support activity in restricted schedule and limited charge, with fixed support personnel and under stated support environment [2].

\subsection{Software Supportability Assessment}

Software supportability assessment is used to assess whether the stated quantitative and qualitative indexes demand of every support combination are achieved. These support combination is prerequisite to support software economically and effectively during the whole life cycle of software [3]. Supportability assessment concentrates on software codes, support document, computer support resources and the plan of life cycle [4].

\section{Foreign Research Situation}

Foreign military always pays much attention to the support problem of software. US troops began to research software support since 1980s. From 1990s, the research in support principle, support mode and support process has a fast development [5]. The American software support research has achieved the following results [6]:

A. US Air Force software technical support center began to compile the software intensive systems acquisition and management guide since $1980 \mathrm{~s}$, and the $3^{\text {rd }}$ version had been released till 1996. The guide investigates the failure cause of existing system, constructs the purchase environment and puts forward tools and software of military for military software purchase. It emphasizes the leading role of software engineering to military software system. Ada language for military development is vigorously advocated, and software reuse technology is actively promoted.

B. USA military starts the research of software maintainability since $1980 \mathrm{~s}$. The classical research is Software Maintenance Assessment Guide written by operational test and evaluation center of Air Force commancon. This guide has been released the $3^{\text {rd }}$ editon until 1997. This guide gives a detailed assessment of software maintenance procedures and methods which means a lot to the launch of military software supportability.

C. American attaches great importance to calculate the cost of military software maintenance. American meets the problem of calculating military software since 1950s. The basic theory and practice system is established in 1980 s and it spreads in 1990s. Parametric cost estimating Manual is released in 1995 and the $2^{\text {nd }}$ edition is released in 1999. Parametric cost estimating advisory group is set up in the lead of Department of Defense Contract Management Command and the Department of Defense Audit. This group is composed by Armed services and industrial sectors, which is responsible for the spread, use, train and research of this method. The method is used in the cost calculation of military software.

D.Due to the particularity of military software maintenance, the maintenance system is inconsistent with the original hardware maintenance system. Depending on the services and arms system, US military uses a variety of software maintenance mode.

\section{The Domestic Research Situation}

\subsection{Qualitative Research}

Literature [2, 7] studies software maintenance from the perspective of the common and different respects of software maintenance and hardware maintenance. The study suggests that there are three categories of factors, the attributes of software itself, the development process of software and the software maintenance resources. In detail, there are the following 9 factors, alternation times, expansion capability, equipment quantity, deployment location, modular, software size, confidentiality, staff skills, standardization, files. Literature [8] induces the factors as the following three categories, software life cycle process, maintenance and support resources. This research uses AHP method to quantize every factor. Then every factor gets its according values by experts. The general evaluation score is counted by a complex equation.

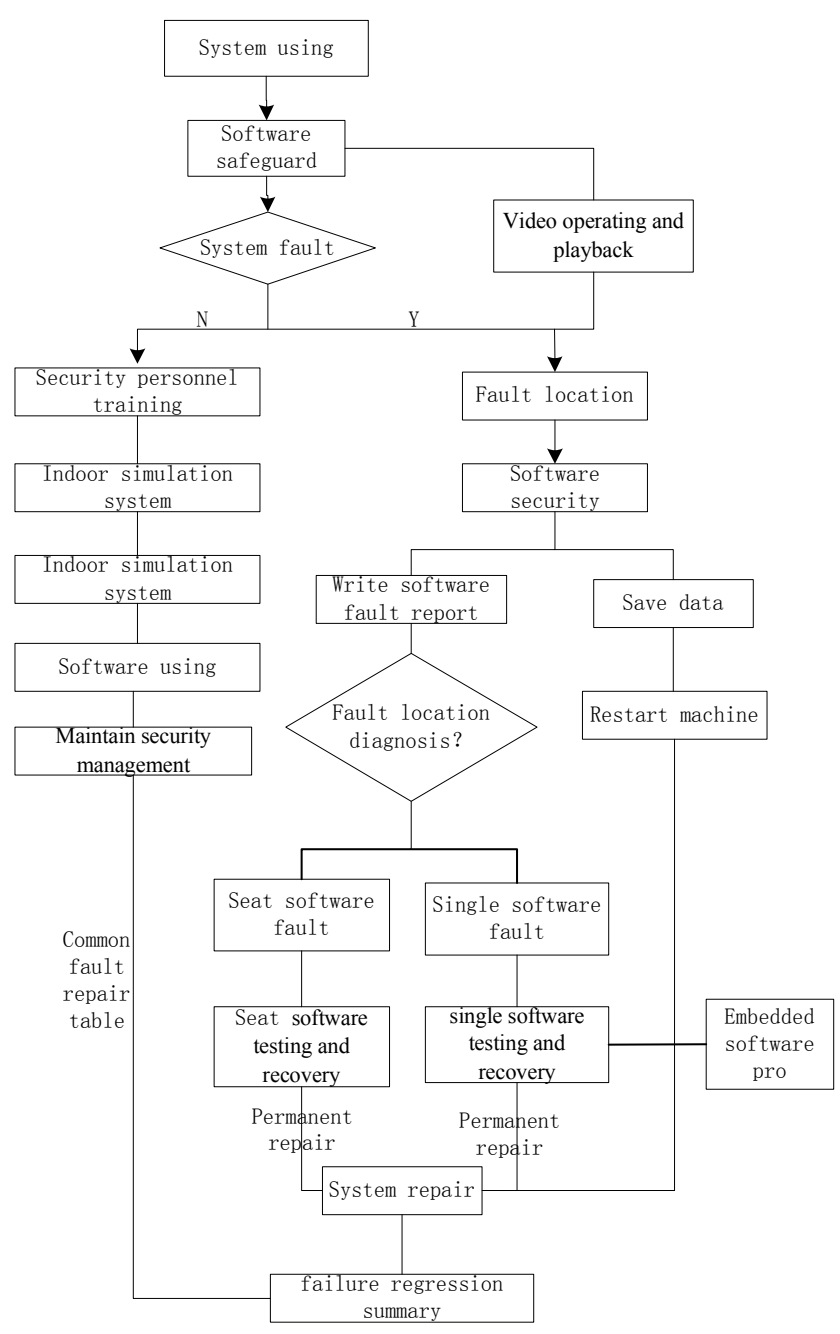

Figure 1. Flow chart of software assurance process. 
To solve the difficult problem of software maintenance for air defense command and control system, the whole maintenance scheme during the software life cycle is researched in literature [9]. The research puts forward a maintenance mode for software. In this literature, it is concluded that the air defense command and control software system should have 6 functions as follows, maintenance and security management, software operation admission and playback, single station software detection and recovery, embedded software programming, command and control simulation system. The software assurance process as shown in Figure 1 is put forward.

In literature [10], the process based software support is studied and a software support model based on process is constructed. Combined with the characteristics of the software, the 9 factors that affect the security of software are put forward. The 9 factors are times used in change, expansion capacity, equipment quantity, deployment location, modularization, software size, confidentiality, personnel skills, standardization and documentation. The software assurance process as shown in Figure 2 is put forward.

It is concluded that the software supportability is a comprehensive attribute, which involves all design features of the software, the whole process of software development, the software environment, software maintenance and software evolution. Closely related with the software security attributes are software reliability, software security, software survive ability and software maintenance. So, improving software security is comprehensive management.

In the literature [11], 5 common methods of software supportability assessment are studied. The 5 sommon methods are as follows, similarity method, simplex method, wholeness method, expert method, computation method. The study suggests that expert method should be a supplement to other methods. In the literature [12], the factors affecting the software supportability are analyzed, and the ways to improve the supportability of the software are studied from the view of the qualitative analysis.

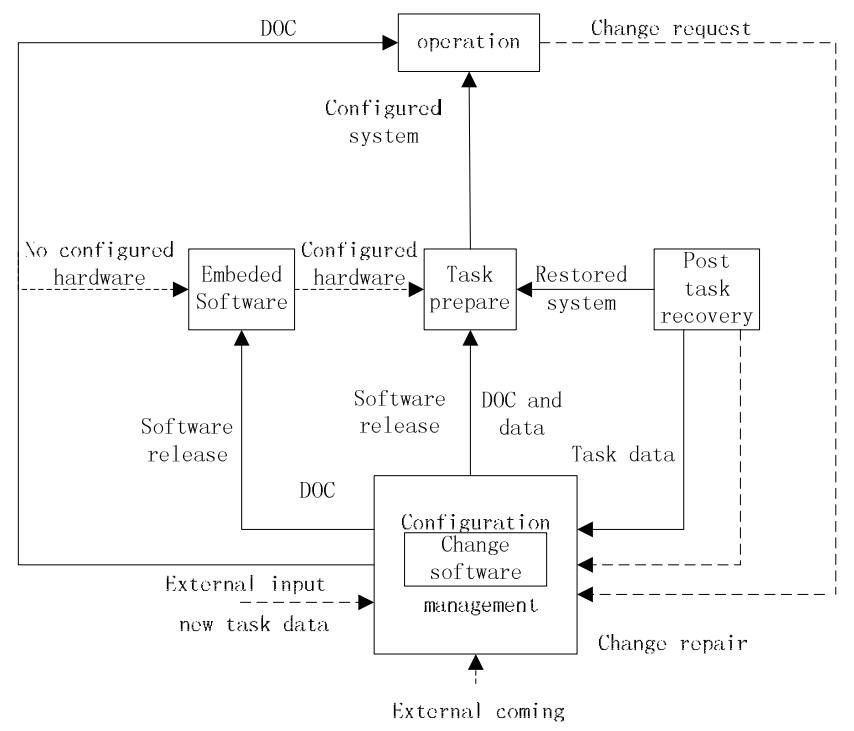

Figure 2. General software security process models.

\subsection{Quantitative Research}

1) Evaluation based on BP neural network and AHP hierarchy analysis

The BP neural network and AHP method (analytic hierarchy process) are applied to the supportability evaluation of equipment in the literature [13-16]. Firstly, The method uses the availability as a parameter to measure the equipment supportability. Secondly, the factors influencing the equipment support are determined. Then, BP neural network and AHP method are used to establish the relationship between the factors and the use of the relationship between every factor. Finally, method for evaluating equipment support is put forward. BP neural network is used to establish the relationship between influencing factors and evaluation indexes and AHP method is used to determine the initial weights of each layer of the neural network.

2) Evaluation based on Fuzzy Theory

A method of uncertain interval attribute evaluation based on fuzzy entropy is studied in literature [18-21]. This method mainly improves the rationality of the weight distribution, which affects the accuracy of impact assessment ranking. So, the method could determine the optimal evaluation scheme under the condition of a large number of uncertain information. This method is essentially a method of determining the rationality of weight distribution which is used to study the problem of how to comprehensively balance the indicators to be evaluated after every influencing factors has been quantized. The research of this paper also considers that the following methods could be used to improve the equipment supportability evaluation, regression analysis, parameter estimation, neural network, grey Analytic Hierarchy Process and so on.

3) Qualitative and quantitative evaluation

Based on the thorough study of the characteristics of software support activities in the whole life cycle, literature [3] analyzes the relationship between the elements of the software supportability and the components of the software. Parameters reflecting software supportability are extracted and organically combined in a certain order and manner, which forms a complete system structure to describe software supportability from different aspects and angles. Finally, the comprehensive index of evaluating software security is obtained by the method of weighted sum of the standard value of each parameter. Based on the comprehensive index, a comprehensive evaluation method of software supportability based on the combination of qualitative and quantitative analysis is proposed.

This method is similar to the research method of neural network. But the weights used in neural network method are quantized which differs the method from neural network method.

\section{Conclusion}

Generally, it could be concluded that qualitative analysis 
research method is used more extensively than quantitative analysis for the research on the evaluation of military equipment supportability. Different qualitative research methods are mainly aimed at the different support nodes in the process of software support and it is less for a comprehensive, systematic study on the evaluation of the supportability process. For quantitative research, the use of neural network evaluation method is more general and the quantitative evaluation methods of different literatures are mainly about the different methods of quantitative assessment of the assessment parameters. Expert scoring method is used in the most part of quantitative assessment methods, which makes the evaluation result influenced by subjective factors. In the next research for software supportability assessment, the evaluation index system and quantitative methods need to be discussed which could get more comprehensive and accurate evaluation results of software supportability.

\section{References}

[1] Zhuwenkui, Zhangfengming, Zhangyu,. Based on the COTS of military software security research, Systems engineering and electronics, 2007, 29 (12): 2166-2170.

[2] Renxinxin, Songtailiang, Liuyixin, etc. Equipped with software protection problem analysis, The 6th international conference on reliability, maintainability, and safety, 2001: 489-493.

[3] Huangjing, Dujiaxing, Yangxueqiang, etc. Based on a new comprehensive evaluation index system of software research, Equipment command technical college journals, 2009, 20 (6): 33-37.

[4] Lizhili, Caohui. New type of weapon equipment software protection research, National defense technology base, 2007 (11): 57-60.

[5] Changlijuan. Preliminary study about improving ship equipment software protection, Computer $\mathrm{CD}$ software and application, 2014: 47-48.

[6] Panli. Military software security research. Shijiazhuang, Thesis of ordnance engineering college, 2002.

[7] Zhouzeyun, Dujiaxing. The difference between hardware and software to ensure security, Journal of armored force engineering institute, 2007, 21 (6): 29-32.

[8] Zhangjunping, Zhuxiaodong, Quhongfei. Software protection assessment in maintainability allocation and the application of the software is expected, Journal of ordnance engineering college, 2008, 20 (2): 5-8.

[9] Shixianguo, Wuqiong, Qiushaofeng, etc. Air defense command and control system software applications, Fire and command control, 2012, 37: 146-148.

[10] Linyuan. Based on the process of software security in the application of modern equipment research, Software Tribune, 2008, 7 (11): 181-183.
[11] Shijianrong, Zhangyong. Software protection evaluation, Standardization of space, 2010 (2): 43-46.

[12] Yaoyuan, Lizhili, Xumeng. Equipped with software protection influence factors analysis and improve the way, Quality and reliability, 2009 (4): 45-47.

[13] Libing, Guohuang, Guojiansheng, etc. The AHP method and BP neural network in the application of the equipment protection evaluation, Journal of $\mathrm{xi}$ 'an aviation technology college, 2007, 25 (5): 23-25, 31.

[14] Zhanghanfeng, Luli, Chenliyun, etc. The air defense weapon system based on BP neural network protection evaluation, Journal of sichuan armaments factories, 2009, 30 (9): 88-90, 99.

[15] Hehailong, Wangqinghai, Wangjingye. Neural network application in the equipment protection evaluation, Systems engineering theory and practice, 2009 (9): 111-116.

[16] Dujiaxing, Huangjing, Bimingguang, etc. Based on the multilevel Petri net software process modeling, Journal of armored force engineering institute, 2008, 22 (6): 47-51.

[17] Zhangjiagnqiang, Zbangtao, Guobo. The maintenance support process multi-level simulation model based on Petri net, Public automation, 2003, 22 (4): 14-17.

[18] Wangyun. The equipment protection evaluation model based on fuzzy entropy, Fire and command control, 2009, 34 (4): 2224.

[19] Wangchunjian, Liuyongzhi, Based on the fuzzy theory of a certain type of protection evaluation, Equipped with environmental engineering, 2007, 4 (4): 45-47, 65.

[20] K. Burak Codur, Ali H. Dogru: Regulations and software evolution: An example from the military domain. Science of Computer Programming, Volume 77, Issue 5, 1 May 2012, pp. 636-643.

[21] Veronica L. Foreman, Francesca M. Favaró, Joseph H. Saleh, Christopher W. Johnson. Software in military aviation and drone mishaps: Analysis and recommendations for the investigation process. Reliability Engineering \& System Safety, Volume 137, May 2015, pp. 101-111.

\section{Biography}

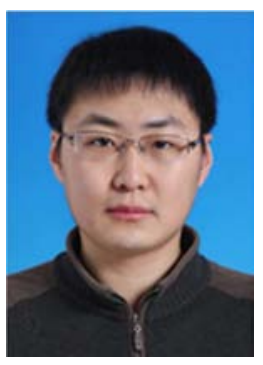

Lv Huiwen, male, was born in Dalian city Liao Ning province of China, in 1985, from 2004.09 to 2008.06 he studied the electronic engineering curriculum in PLA information engineering university, and obtained the Bachelor's degree in 2008, In the 2009, he entered the Beijing university for pursuing his MS degree, and in 2012 he graduated graduated from the school of software and microelectronics of Beijing university. And got the Master degree of information network security. From 2013.03 - until now, he works at equipment academy for his $\mathrm{PhD}$, And his research direction is comprehensive security theory and technology. 